\title{
Uric Acid as a Risk Factor for Chronic Kidney Disease and Cardiovascular Disease \\ - Japanese Guideline on the Management of Asymptomatic Hyperuricemia -
}

\author{
Ichiro Hisatome, MD, PhD; Peili Li, MD, PhD; Junichiro Miake, MD, PhD; \\ Fikri Taufiq, MD, PhD; Endang Mahati, MD, PhD; Nani Maharani, MD, PhD; \\ Sulistiyati Bayu Utami, MD, PhD; Masanari Kuwabara, MD, PhD; \\ Udin Bahrudin, MD, PhD; Haruaki Ninomiya, MD, PhD
}

\begin{abstract}
Serum uric acid (UA) is taken up by endothelial cells and reduces the level of nitric oxide (NO) by inhibiting its production and accelerating its degradation. Cytosolic and plasma xanthine oxidase (XO) generates superoxide and also decreases the NO level. Thus, hyperuricemia is associated with impaired endothelial function. Hyperuricemia is often associated with vascular diseases such as chronic kidney disease (CKD) and cardiovascular disease (CVD). It has long been debated whether hyperuricemia is causally related to the development of these diseases. The 2020 American College of Rheumatology Guideline for the Management of Gout (ACR2020) does not recommend pharmacological treatment of hyperuricemia in patients with CKD/CVD. In contrast, the Japanese Guideline on Management of Hyperuricemia and Gout (JGMHG), $3^{\text {rd }}$ edition, recommends pharmacological treatment of hyperuricemia in patients with CKD. In a FREED study on Japanese hyperuricemic patients with CVD, an XO inhibitor, febuxostat, improved the primary composite endpoint of cerebro-cardio-renovascular events, providing a rationale for the use of urate-lowering agents (ULAs). Since a CARES study on American gout patients with CVD treated with febuxostat revealed increased mortality, ACR2020 recommends switching to different ULAs. However, there was no difference in the mortality of Japanese patients between the febuxostat-treated group and the placebo or allopurinol-treated groups in either the FEATHER or FREED studies.
\end{abstract}

Key Words: Cardio-renal continuum; CARES study; Urate-lowering agent; Uric acid transporter; Xanthine oxidase

$\mathbf{H}$ yperuricemia is defined as a serum uric acid (UA) level $>7.0 \mathrm{mg} / \mathrm{dL} .{ }^{1}$ It occurs in $20 \%$ of men and in $5 \%$ of women in the entire adult Japanese population. ${ }^{1}$ It can be caused by genetic mutations or polymorphisms that accelerate the production of UA or reduce its excretion. ${ }^{1}$ In addition, a diverse set of environmental factors contribute to its development. Typical symptomatic complications of hyperuricemia are gout and ureteral calculus, caused by monosodium urate (MSU) crystals. Even in the absence of these complications, asymptomatic hyperuricemia is frequently associated with lifestyle-related diseases. Although it is also associated with vascular diseases such as chronic kidney disease (CKD) and cardiovascular disease (CVD), it remains unclear whether hyperuricemia is causally related to the development of these diseases. The Japanese Guideline on the Management of Hyperuricemia and Gout (JGMHG), $2^{\text {nd }}$ edition, ${ }^{1}$ recommends pharmacological treatment of asymptomatic hyperuricemia, whereas Western guidelines such as the 2020 American College of Rheumatology Guideline for the Management of Gout ${ }^{2}$ (ACR 2020), do not. In this review, we discuss how hyperuricemia relates to vascular diseases

Received May 8, 2020; revised manuscript received October 4, 2020; accepted November 15, 2020; J-STAGE Advance Publication released online December 18, 2020

Division of Regenerative Medicine and Therapeutics, Department of Genetic Medicine and Regenerative Therapeutics, Institute of Regenerative Medicine and Biofunction, Tottori University Graduate School of Medical Science, Yonago (I.H., P.L.); Department of Pharmacology (J.M.), Department of Biological Regulation (H.N.), Tottori University Faculty of Medicine, Yonago, Japan; Department of Physiology, Faculty of Medicine, Sultan Agung Islamic University, Semarang (F.T.); Department of Pharmacology and Therapy (E.M., N.M.), Department of Cardiology and Vascular Medicine (S.B.U., U.B.), Faculty of Medicine, Diponegoro University, Semarang, Indonesia; and Intensive Care Unit and Department of Cardiology, Toranomon Hospital, Tokyo (M.K.), Japan

Mailing address: Ichiro Hisatome, MD, PhD, Division of Regenerative Medicine and Therapeutics, Department of Genetic Medicine and Regenerative Therapeutic, Tottori University Faculty of Medicine, 36-1 Nishicho, Yonago 683-8504, Japan. E-mail: hisatome@tottori-u.ac.jp

All rights are reserved to the Japanese Circulation Society. For permissions, please e-mail: cj@j-circ.or.jp

ISSN-1346-9843 


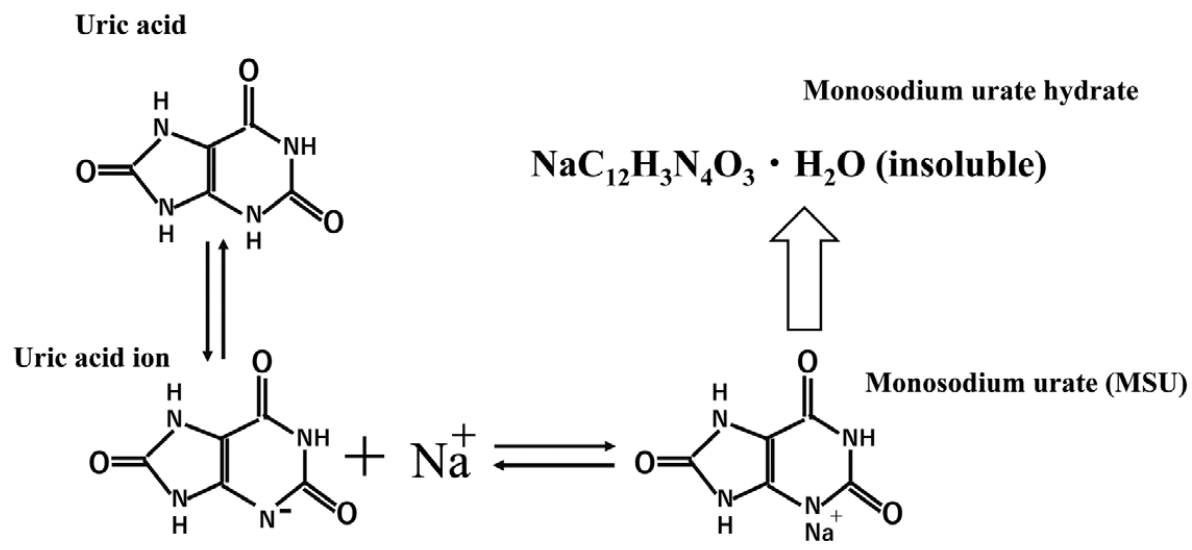

Figure 1. Generation of uric acid ion, monosodium urate and monosodium urate hydrate from uric acid. Uric acid in solution gives rise to uric acid ion with a negative charge. This uric acid ion reacts with $\mathrm{Na}^{+}$, yields to soluble monosodium urate (MSU), which then gives rise to insoluble monosodium urate hydrate.

and present evidence of the benefit of pharmacological treatment of asymptomatic hyperuricemia, focusing on the difference between the JGMHG $3^{\text {rd }}$ edition $^{3}$ and ACR $2020 .^{2}$

\section{Definition of Hyperuricemia}

Ever since the evolutionary loss of uricase activity, UA has been the end product of the human body's purine metabolism. The ionized forms of UA in solution easily form MSU. When the concentration of MSU exceeds the solubility, MSU binds with water molecules to form crystals as MSU monohydrate (Figure 1). Because a $140 \mathrm{mmol} / \mathrm{L} \mathrm{NaCl}$ solution is saturated with $\mathrm{MSU}$ at $6.8 \mathrm{mg} / \mathrm{dL}$ at $37^{\circ} \mathrm{C}, \mathbf{4 , 5}$ ACR $2020^{2}$ defines hyperuricemia as serum UA (SUA) $>6.8 \mathrm{mg} / \mathrm{dL}$ (Table 1). And as the solubility of MSU in the serum is slightly higher than the saturation value of $6.8 \mathrm{mg} / \mathrm{dL},{ }^{6} \mathrm{JGMHG}$ defines hyperuricemia as SUA $>7 \mathrm{mg} / \mathrm{dL}^{1,3}$ (Table 1). When the UA level is $>7 \mathrm{mg} / \mathrm{dL}$ in the joint fluid, MSU crystals are generated and taken up by macrophages, causing gout. Based on the evidence showing that hyperuricemia increases the chance of developing gout, ${ }^{7}$ $\mathrm{JGMHG}^{\mathbf{1}, \mathbf{3}}$ recommends administration of a urate-lowering agent (ULA) to treat asymptomatic hyperuricemia (Table 1). This recommendation was supported by a FEATHER study ${ }^{8}$ that followed patients with asymptomatic hyperuricemia for 3 years and revealed a decreased incidence of gout in those treated with febuxostat $(2 / 219$ : $0.9 \%)$ compared to those treated with placebo $(13 / 222$ : $5.9 \%$ ). In contrast, because of the limited effect, ACR $2020^{2}$ does not recommend administration of ULAs to patients with asymptomatic hyperuricemia (Table 1).

\section{Association of Asymptomatic Hyperuricemia With Lifestyle-Related Diseases, CKD and CVD}

As the SUA level is determined by the balance between its production and excretion, the pathophysiological mechanisms of hyperuricemia have been categorized into 3 types; that is, the overproduction type; the renal underexcretion type; and the mixed type. ${ }^{9}$ Recently, it was demonstrated that a UA transporter ATP-binding cassette superfamily $\mathrm{G}$ member 2 (ABCG2) appeared in the intestine where it transports UA to stool. ${ }^{10}$ Loss of function due to mutation of the $A B C G 2$ gene increases SUA and causes gout. ${ }^{11}$ Thus, the reduced extra-renal excretion type was categorized as a novel pathophysiological mechanism. ${ }^{11}$

Asymptomatic hyperuricemia is frequently associated with lifestyle-related diseases such as hypertension, ${ }^{12}$ diabetes mellitus, ${ }^{13}$ metabolic syndrome ${ }^{14}$ and non-alcoholic fatty liver disease, ${ }^{15}$ and vascular diseases such as $\mathrm{CKD}^{16}$ and CVD. ${ }^{17-19}$ These diseases are known to be associated with insulin resistance. ${ }^{20}$ In renal proximal tubular cells, UA is reabsorbed by the urate transporter 1 (URAT1) localized on the luminal side. ${ }^{21}$ Hyperinsulinemia caused by insulin resistance enhances both the activity and protein expression of URAT $1,{ }^{22}$ hence facilitating the reabsorption of $\mathrm{UA}^{23}$ and increasing SUA.

\section{Hyperuricemia and Endothelial Function}

Hyperuricemia is associated with vascular diseases. It has long been debated whether hyperuricemia may be causally related to the development of these diseases. The endothelium preserves vascular tone. Vasodilation induced by both acetylcholine administration and sheer stress is attributable to nitric oxide (NO) production of the endothelium. ${ }^{24}$ Thus, the impaired vasodilation is characterized as impaired endothelial function. ${ }^{24,25}$ Although impaired endothelial function causes CVD and CKD, ${ }^{26}$ it is also associated with hyperuricemia. ${ }^{27}$ Several lines of evidence support potential links between hyperuricemia and impaired endothelial function.

\section{UA and Endothelial Function}

Accumulating evidence indicates that hyperuricemia impairs vasodilation induced by NO production. The flowmediated vasodilation in the forearm artery by sheer stress was impaired in hyperuricemic patients. ${ }^{27,28}$ UA infusion into the brachial artery of healthy volunteers resulted in impaired vasodilation of the forearm artery in response to acetylcholine. ${ }^{29} \mathrm{UA}$ reduced NO production and inhibited 


\begin{tabular}{|c|c|c|c|}
\hline & & JGMHD $3^{\text {rd }}$ Edition & ACR2020 Guidelines \\
\hline \multirow{5}{*}{$\begin{array}{l}\text { Guideline } \\
\text { development } \\
\text { method }\end{array}$} & The clinical questions & $\begin{array}{l}\text { Determined by voting among Guideline development } \\
\text { group based on GRADE approach }\end{array}$ & $\begin{array}{l}\text { Determined by voting among panel } \\
\text { members based on GRADE approach }\end{array}$ \\
\hline & $\begin{array}{l}\text { The systematic } \\
\text { review }\end{array}$ & $\begin{array}{l}\text { Guideline development group provide the key words } \\
\text { to Japanese Medical Library Association, which } \\
\text { collects reports, and then Guideline development } \\
\text { group conduct SR }\end{array}$ & The voting panel conduct SR \\
\hline & $\begin{array}{l}\text { The evaluation of } \\
\text { body of evidence }\end{array}$ & $\begin{array}{l}\text { Certainty of balance between benefit and harm } \\
\text { based on GRADE approach }\end{array}$ & $\begin{array}{l}\text { Certainty of balance between benefit and } \\
\text { harm based on GRADE approach }\end{array}$ \\
\hline & $\begin{array}{l}\text { The patient } \\
\text { contribution }\end{array}$ & $\begin{array}{l}\text { Patients provided the information of their value and } \\
\text { preference }\end{array}$ & $\begin{array}{l}\text { Patients participate in voting of } \\
\text { recommendation as the voting panel }\end{array}$ \\
\hline & $\begin{array}{l}\text { The determination of } \\
\text { recommendation }\end{array}$ & $\begin{array}{l}\text { Determined by voting among Guideline development } \\
\text { group referred to strength of evidence, cost and } \\
\text { resources, and value and preference }\end{array}$ & $\begin{array}{l}\text { Determined by voting among voting panel } \\
\text { including patients referred to strength of } \\
\text { evidence, cost and resources, and value } \\
\text { and preference }\end{array}$ \\
\hline \multirow[t]{7}{*}{ Statement } & $\begin{array}{l}\text { Definition of } \\
\text { hyperuicemia }\end{array}$ & $\mathrm{SUA}>7.0 \mathrm{mg} / \mathrm{dL}$ & $\mathrm{SUA}>6.8 \mathrm{mg} / \mathrm{dL}$ \\
\hline & $\begin{array}{l}\text { Target to treat for } \\
\text { gout }\end{array}$ & Below $6 \mathrm{mg} / \mathrm{dL}$ & Less than $6 \mathrm{mg} / \mathrm{dL}$ \\
\hline & $\begin{array}{l}\text { Asymptormatic } \\
\text { hyperuricemia } \\
\text { without complication }\end{array}$ & $\begin{array}{l}\text { Considering the use of ULA at SUA } \geq 9 \mathrm{mg} / \mathrm{dL} \text { and } \\
\text { target to SUA } \leq 6 \mathrm{mg} / \mathrm{dL}\end{array}$ & \multirow[t]{2}{*}{$\begin{array}{l}\text { Pharmacological treatment of asymptomatic } \\
\text { hyperuricemia is not recommended }\end{array}$} \\
\hline & $\begin{array}{l}\text { Asymptormatic } \\
\text { hyperuricemia with } \\
\text { complication }\end{array}$ & $\begin{array}{l}\text { Considering the use of ULA at SUA } \geq 8 \mathrm{mg} / \mathrm{dL} \text { and } \\
\text { target to SUA } \leq 6 \mathrm{mg} / \mathrm{dL}\end{array}$ & \\
\hline & $\begin{array}{l}\text { Asymptormatic } \\
\text { hyperuricemia with } \\
\text { renal disease }\end{array}$ & $\begin{array}{l}\text { The use of ULAs to retard the decline in kidney } \\
\text { function is conditionally recommended in patients } \\
\text { with hyperuricemia and renal disease }\end{array}$ & \multirow[t]{3}{*}{$\begin{array}{l}\text { The benefit of ULAs in asymptomatic } \\
\text { hyperuricemia has yet to be established }\end{array}$} \\
\hline & $\begin{array}{l}\text { Asymptormatic } \\
\text { hyperuricemia with } \\
\text { hypertension }\end{array}$ & $\begin{array}{l}\text { The use of ULAs to improve life prognosis and } \\
\text { reduce the risk of CVD cannot be conditionally } \\
\text { recommended for hypertensive patients with } \\
\text { hyperuricemia }\end{array}$ & \\
\hline & $\begin{array}{l}\text { Asymptormatic } \\
\text { hyperuricemia with } \\
\text { heart failure }\end{array}$ & $\begin{array}{l}\text { The use of ULAs to improve life prognosis and } \\
\text { reduce the risk of CVDs cannot be conditionally } \\
\text { recommended for patients with heart failure and } \\
\text { hyperuricemia }\end{array}$ & \\
\hline
\end{tabular}

ACR2020 Guidelines, 2020 American College of Rheumatology Guideline for the Management of Gout; CVD, cardiovascular disease; JGMHD $3^{\text {rd }}$ edition, Japanese Guideline on Management of Hyperuricemia and Gout, $3^{\text {rd }}$ edition; SR, systematic review; SUA, serum uric acid; ULA, uratelowering agent.

its vasodilation induced by administration of acetylcholine in rat and mouse aortic arteries. ${ }^{30,31}$ This effect of UA is apparently exerted by UA in the intracellular space of endothelial cells, taken up through UA transporters (UATs), because the reduced NO production by UA in endothelial cells was eliminated by UATs inhibitors. ${ }^{21,32-34}$ UATs such as URAT1, UA transporter voltage-dependent 1 (URATv1), Monocarboxylate Transporters 9 (MCT9), ABCG2 and Multidrug resistance protein 4 (MRP4) are ubiquitously expressed in tissues including endothelial cells. ${ }^{35}$ URAT1, URATV1 and MCT9 belong to the influx transporters that absorb UA, whereas ABCG2 and MRP4 belong to the efflux transporters that secrete UA. Hyperuricemia increases the intracellular level of UA, which was proven by using ${ }^{14} \mathrm{C}$-labeled UA. ${ }^{36,37}$ Of these influx transporters, URAT1 or URATV1 is responsible for absorption of UA by endothelial cells. ${ }^{32,35,37,38}$

Within the endothelial cells, UA reduces the level of NO in response to acetylcholine both by inhibiting its production and accelerating its degradation. NO is generated by endothelial NO synthase (eNOS). ${ }^{39}$ Acetylcholine activates the phosphoinositide 3-kinases (PI3 kinase)/Ak strain transforming (Akt) pathway that results in phosphorylated eNOS-Ser ${ }^{1177}$. This phosphorylated eNOS is the active form that can bind to calmodulin (CaM), resulting in the production of NO from L-arginine. ${ }^{39}$ Intracellular UA activates phosphatase and tensin homolog deleted from chromosome 10 (PTEN) and decreases eNOS-Ser ${ }^{1177}$ phosphorylation, and inhibits NO production. ${ }^{31}$ Besides, intracellular UA activates protein kinase $\mathrm{C}(\mathrm{PKC})$ that phosphorylates eNOS-Thr ${ }^{495}$ and attenuates its binding to $\mathrm{CaM}$, resulting in reduced $\mathrm{NO}$ production. ${ }^{31,40}$ These inhibitory effects of UA on $\mathrm{NO}$ production were attenuated by anti-oxidants, suggesting the involvement of superoxide. In fact, UA facilitates assembly of nicotinamide adenine dinucleotide phosphate (NADPH) oxidase subunits on the membrane, and produces superoxides, ${ }^{\mathbf{4 1}}$ which reduces NO level by inhibiting its production and accelerating its degradation (Figure 2).

\section{Xanthine Oxidase (XO) and Endothelial Function}

Xanthine oxidoreductase (XOR) is the central player in the formation of UA and it also generates superoxide. XOR is composed of 2 components: xanthine dehydrogenase $(\mathrm{XDH})$ and $\mathrm{XO} . \mathrm{XO}$ is generated from XDH by posttranslational modification and catalyses the last 2 steps of reactions that convert hypoxanthine to xanthine, and xanthine to UA. These reactions yield superoxide and 


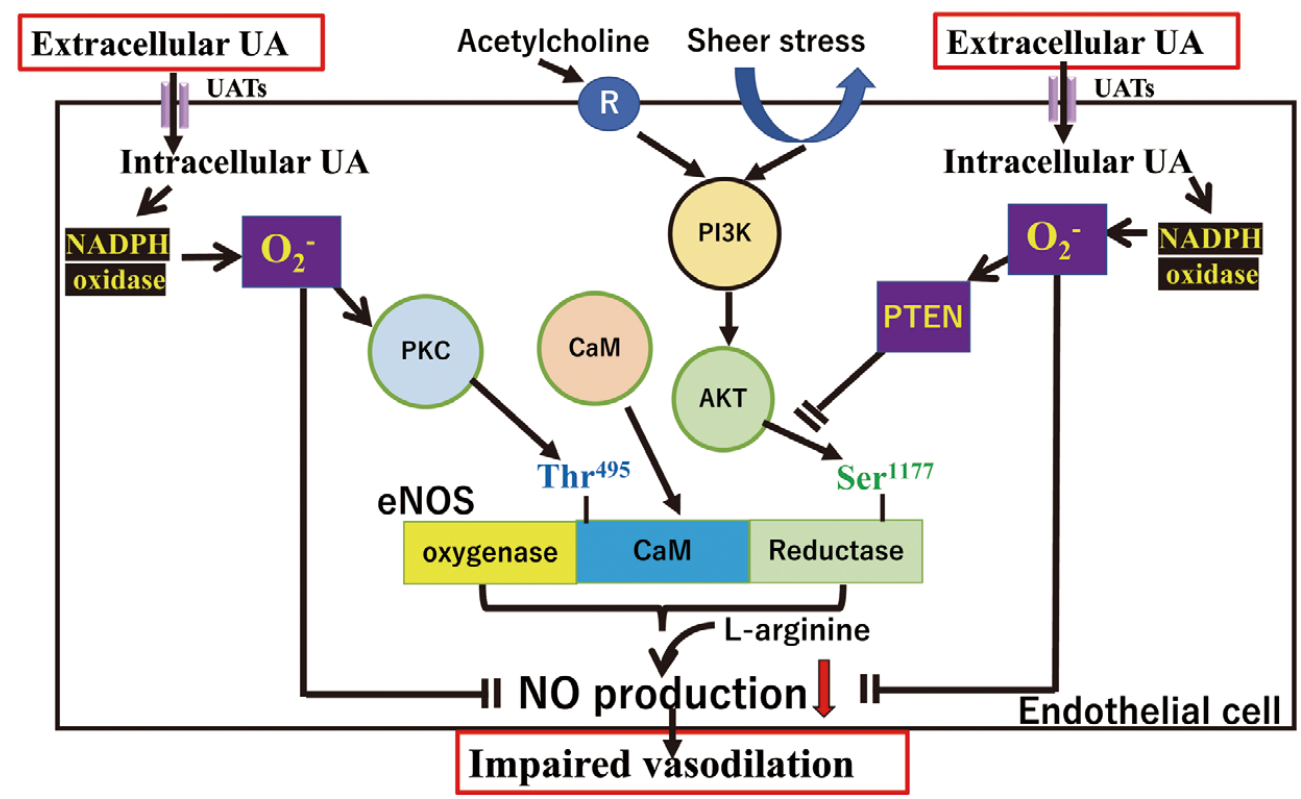

Figure 2. UA and endothelial function. Both acetylcholine and sheer stress activate the PI3K-AKT pathway, by which eNOS-Ser ${ }^{1177}$ is phosphorylated, and its binding to CaM is facilitated. Intracellular UA activates NADPH oxidase, which generates superoxide $\left(\mathrm{O}_{2}{ }^{-}\right) . \mathrm{O}_{2}-$ reacts with $\mathrm{NO}$, and degrades it. $\mathrm{O}_{2}^{-}$activates PTEN and dephosphorylates eNOS-Ser ${ }^{1177}$, reducing NO production. $\mathrm{O}_{2}{ }^{-}$also activates PKC and phosphorylates eNOS-Thr ${ }^{495}$, inhibiting NO production. UATs, uric acid transporters; R, receptors; UA, uric acid; NADPH, nicotinamide adenine dinucleotide phosphate; PI3K, phosphoinositide 3-kinases; AKT, AK strain transforming; PTEN, phosphatase and tensin homolog deleted from chromosome 10; PKC, protein kinase C; eNOS, endothelial nitric oxide synthase; CaM, calmodulin; NO, nitric oxide; uric acid; Ser, serine; Thr, threonine.

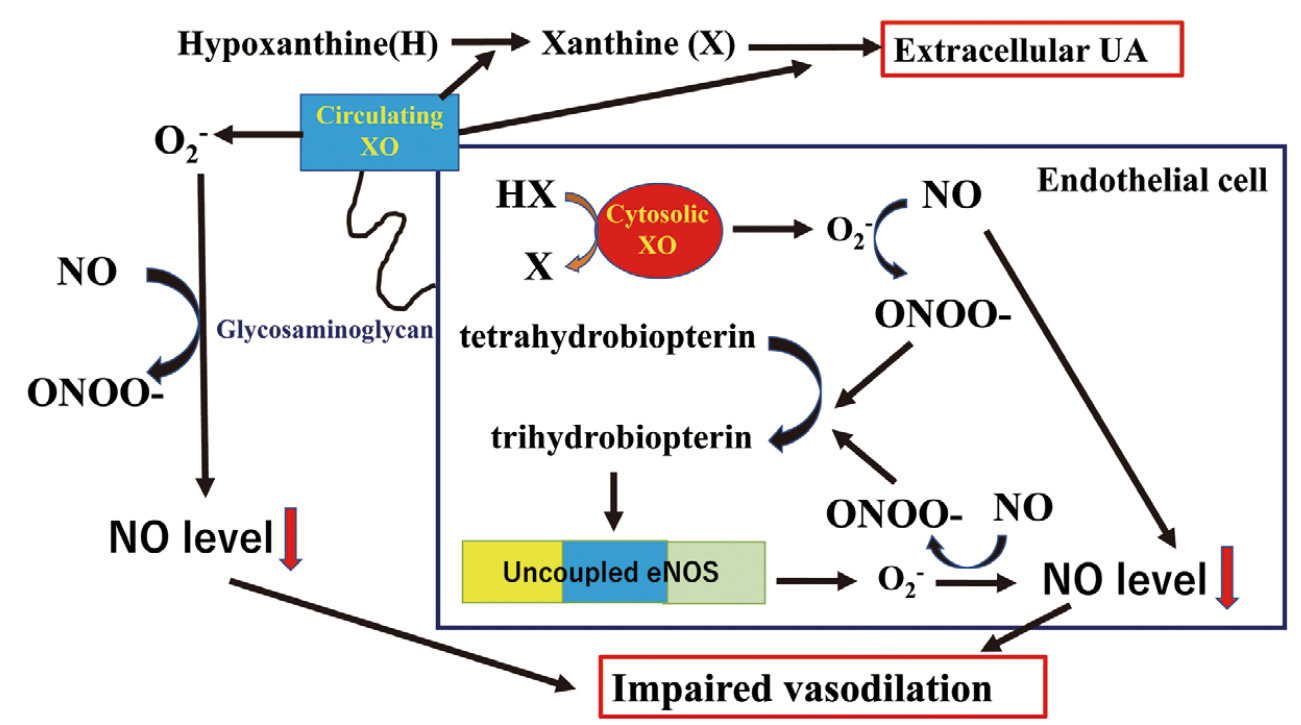

Figure 3. Xanthine oxidase and endothelial function. By converting hypoxanthine to xanthine and UA, circulating and cytosolic $\mathrm{XO}$ generates superoxide. $\mathrm{O}_{2}{ }^{-}$degrades $\mathrm{NO} . \mathrm{O}_{2}{ }^{-}$reacts with $\mathrm{NO}$ and produces peroxynitrite, reduces tetrahydrobiopterin and converts eNOS to a superoxide-generating enzyme. Both circulating and cytosolic XO can impair vasodilation. eNOS, endothelial nitric oxide synthase; $\mathrm{O}_{2}^{-}$, superoxide; $\mathrm{NO}$, nitric oxide; $\mathrm{ONOO}^{-}$, peroxynitrite; $\mathrm{XO}$, xanthine oxidase. 


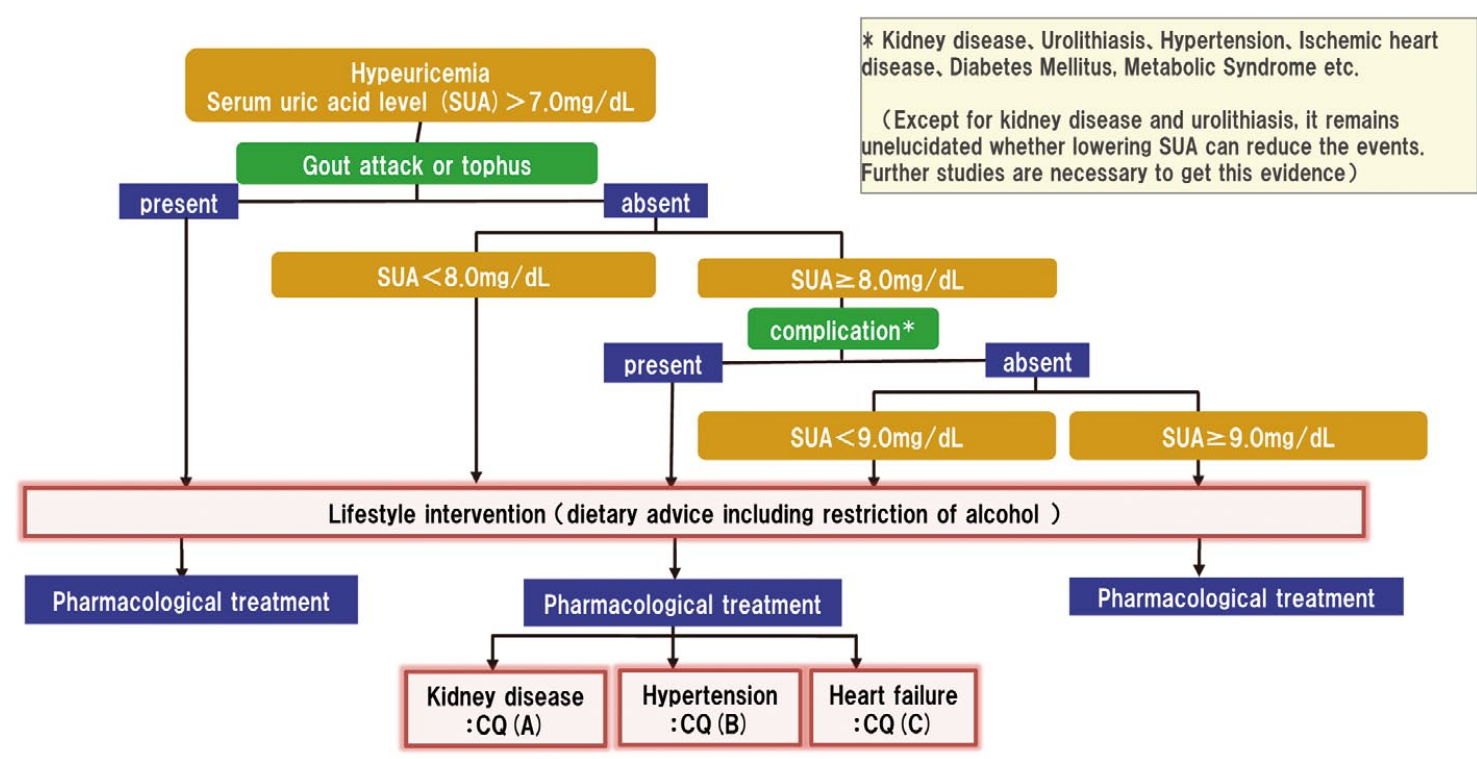

Figure 4. Flowchart for the medical treatment of hyperuricemia and gout. In patients with a SUA $\geq 8 \mathrm{mg} / \mathrm{dL}$ who have complications such as CKD, hypertension, heart failure etc., treatment with ULAs should be considered after life-style modifications. The recommendation by JGMHD 3rd edition on the use of ULAs in patients with CKD, hypertension or heart failure has been described, in part, by clinical questions (CQ) (A), CQ (B) or CQ (C) in the text, respectively. SUA, serum uric acid; CKD, chronic kidney disease; JGMHD $3^{\text {rd }}$ edition, Japanese Guideline on Management of Hyperuricemia and Gout, $3^{\text {rd }}$ edition; ULAs, urate-lowering agent.

hydrogen peroxide..$^{42} \mathrm{XO}$ is highly active in the liver and small intestine, but it also exists both in the cytoplasm and on the surface of endothelial cells. Superoxide generated by $\mathrm{XO}$ reacts directly with NO, resulting not only in decreased NO but also increased peroxynitrite. Peroxynitrite can oxidize and inactivate tetrahydrobiopterin. In the absence of tetrahydrobiopterin, eNOS is converted into a superoxidegenerating enzyme. ${ }^{43}$ Recently, $\mathrm{XO}$ was found to exist in plasma. ${ }^{44}$ This circulating $\mathrm{XO}$ is believed to be released from XOR-rich organs such as the liver. It binds glycosaminoglycans on the surface of endothelial cells. ${ }^{45}$ Superoxide produced by endothelium-bound $\mathrm{XO}$ reacts with $\mathrm{NO}$, yields peroxynitrite and attenuates the NO-dependent production of cGMP by smooth muscle cells (Figure 3). ${ }^{\mathbf{4 6}}$

\section{UA as an Antioxidant}

In the extracellular space, UA is known to be one of the most potent antioxidants. It can scavenge superoxide, hydroxyl radicals and singlet oxygen and can chelate transition metals. It is thought to be responsible for neutralizing more than $50 \%$ of the free radicals in human blood ${ }^{47}$ In addition, UA at physiological levels prevents hydrogen peroxide-induced inactivation of superoxide dismutase, an antioxidant enzyme capable of removing superoxide anion radicals. ${ }^{48}$ Given the role of SUA as an antioxidant, an extreme reduction could also impair endothelial functions. This was proven by the measurements of the flow-mediated dilatation of the forearm artery, ${ }^{49}$ and exercise-induced constriction of the renal artery ${ }^{\mathbf{5 0}}$ in renal hypouricemic patients. The J-shaped association between SUA levels and cardiovascular event risks had been observed in epidemiological studies, ${ }^{\mathbf{5 1 , 5 2}}$ indicating that low levels of SUA are associated with a higher risk of cardio- vascular events as much as high levels of SUA.

\section{The Japanese Guideline on the Management of Hyperuricemia and Gout}

Despite the lines of evidence for asymptomatic hyperuricemia as a risk factor for CKD and CVD, the use of ULAs is still controversial. The JGMHG $2^{\text {nd }}$ edition ${ }^{1}$ recommends ULAs to prevent gout, CKD and CVD. Multinational evidence-based recommendations did not reveal a benefit of pharmacological treatment of asymptomatic hyperuricemisa. ${ }^{53}$ ACR $2020^{2}$ stated that, although there are associations between hyperuricemia and other comorbid conditions such as hypertension, CVD and CKD, ${ }^{54}$ the benefit of ULA in the absence of gout has yet to be established..$^{55}$

In the JGMHG $3^{\text {rd }}$ edition published in $2018,{ }^{3}$ the rationality of pharmacological treatment has been evaluated based on the GRADE method ${ }^{\mathbf{5 6}}$ recommended by Medical Information Network Distribution Services. ${ }^{57}$ The flow chart and clinical questions (CQs) for treating hyperuricemia associated with CKD, hypertension or heart failure as CVD are shown in Figure 4.

As for the pharmacological treatment of hyperuricemia with CKD (CQ (A): Table 2), the beneficial outcome was the "inhibition of decline in renal function". Five randomized control trials (RCTs) examined the change in the estimated glomerular filtration rate (eGFR). ${ }^{58-62}$ A metaanalysis, with patients in the ULA intervention group and subjects in the control group, showed a statistically significant improvement in eGFR in the ULA intervention group. ${ }^{3}$ Three RCTs assessed another beneficial outcome as the "inhibition of end-stage renal failure". A meta-analysis indicated that all studies found the frequency of end-stage renal failure was significantly low in the ULA intervention 


\begin{tabular}{|c|c|c|}
\hline \multicolumn{3}{|c|}{ CQ (A): Can urate-lowering agents be recommended in patients with hyperuricemia and kidney injury over non-medication? } \\
\hline Recommendation & $\begin{array}{l}\text { Strength of } \\
\text { recommendation }\end{array}$ & $\begin{array}{l}\text { Certainty in } \\
\text { evidence }\end{array}$ \\
\hline $\begin{array}{l}\text { The use of urate-lowering agents to retard the decline in kidney function is } \\
\text { conditionally recommended in patients with hyperuricemia and kidney injury. }\end{array}$ & $\begin{array}{l}\text { It is conditionally } \\
\text { recommended. }\end{array}$ & B (moderate) \\
\hline \multicolumn{3}{|c|}{ CQ (B): Can urate-lowering agents be recommended for hypertensive patients with hyperuricemia over non-medication treatment } \\
\hline Recommendation & $\begin{array}{l}\text { Strength of } \\
\text { recommendation }\end{array}$ & $\begin{array}{l}\text { Certainty in } \\
\text { evidence }\end{array}$ \\
\hline $\begin{array}{l}\text { The use of urate-lowering agents to improve life prognosis and reduce the risk of } \\
\text { cardiovascular disease cannot be conditionally recommended for hypertensive } \\
\text { patients with hyperuricemia. }\end{array}$ & $\begin{array}{l}\text { It is not conditionally } \\
\text { recommended. }\end{array}$ & D (very weak) \\
\hline \multicolumn{3}{|c|}{$\begin{array}{l}\mathrm{CQ}(\mathrm{C}) \text { : Can urate-lowering agents be recommended for patients with heart failure and hyperuricemia over non-medication } \\
\text { treatment? }\end{array}$} \\
\hline Recommendation & $\begin{array}{l}\text { Strength of } \\
\text { recommendation }\end{array}$ & $\begin{array}{l}\text { Certainty in } \\
\text { evidence }\end{array}$ \\
\hline $\begin{array}{l}\text { The use of urate-lowering agents to improve life prognosis and reduce the risk of } \\
\text { cardiovascular disease cannot be conditionally recommended for patients with } \\
\text { heart failure and hyperuricemia. }\end{array}$ & $\begin{array}{l}\text { It is not conditionally } \\
\text { recommended. }\end{array}$ & C (weak) \\
\hline
\end{tabular}

$\mathrm{CKD}$, chronic kidney disease; $\mathrm{CQ}$, clinical question.

group. ${ }^{3}$ The harmful outcome of "an increase in adverse effects" was examined in 3 RCTs. ${ }^{\mathbf{6 2}-64}$ There was no difference observed in the onset of adverse events between the ULA intervention group and the control group. Thus, ULAs improved the renal function and suppressed the onset of end-stage renal failure in CKD patients, and there was no significant difference in adverse effects between ULA-treatment and placebo groups, ${ }^{\mathbf{6 0 , 6 3 , 6 4}}$ indicating that the benefit of ULAs is over the harm. ULAs are conditionally recommended for use in hyperuricemic patients with CKD because the strength of the evidence was determined to be moderate $(\mathrm{B})$.

As for the pharmacological treatment of hyperuricemia with hypertension (CQ (B): Table 2), the beneficial outcome was the "inhibition of cardiovascular events". Two observational studies demonstrated that the risk of cardiovascular events was reduced in patients receiving allopurinol. ${ }^{65,66} \mathrm{~A}$ meta-analysis found that use of allopurinol was associated with a significant reduction in the risk of cardiovascular events. There were no papers from which it was possible to evaluate another beneficial outcome, a "reduction in cardiovascular mortality". A meta-analysis was conducted by the Cochrane Library ${ }^{67}$ using 3 prospective interventional studies comparing the effect of allopurinol and placebo to evaluate an "increase in adverse effects". There was no difference in the onset of adverse events between the ULA intervention group and the placebo group. It stated that the use of ULAs to improve patients' prognosis and reduce the risk of CVD cannot be conditionally recommended for hypertensive patients with hyperuricemia because the strength of the evidence was determined to be extremely weak (D).

As for the pharmacological treatment of hyperuricemia with heart failure (CQ (C): Table 2), the beneficial outcome was "reduced cardiovascular events". There were 2 RCTs $;{ }^{\mathbf{6 8 , 6 9}}$ however, neither found a significant difference between the ULA intervention group and the placebo group. Two RCTs evaluated another beneficial outcome, "reduced overall mortality", ${ }^{68,69}$ and neither found a significant difference in the overall mortality between the
ULA intervention group and the placebo group. There was one $\mathrm{RCT}^{69}$ that evaluated an "increase in adverse effects" and found no significant difference between the ULA intervention group and the placebo group. It stated that the use of ULAs to improve life prognosis and reduce the risk of CVD cannot be conditionally recommended for patients with heart failure and hyperuricemia because the strength of the evidence was determined to be weak (C).

Further studies are required to verify the rationality of pharmacological treatment of asymptomatic hyperuricemia patients with hypertension or heart failure. Recently, a FREED study ${ }^{70}$ reported that febuxostat improved the primary composite endpoint of cerebro-cardio-reno-vascular events in hyperuricemic patients with hypertension, diabetes and cerebro-cardio-reno-vascular disease. This improvement was caused by protecting renal function, indicating that improvement in renal function restores cardiac function (cardio-renal continuum).

\section{ACR2020 Recommendation for the Use of a XO Inhibitor in Patients With Gout and Cardiovascular Events}

According to the ACR Guideline 2020, ${ }^{2}$ switching from febuxostat to an alternative ULA is conditionally recommended for patients with a history of CVD events. In the CARES trial of febuxostat vs. allopurinol, 71 there was no difference in the primary composite CVD endpoint between the two. However, febuxostat was associated with a higher risk of CVD-related death and all-causes mortality compared with allopurinol. It was not associated with any other secondary CVD outcomes such as non-fatal myocardial infarction, non-fatal stroke, or urgent revascularization for unstable angina. Because of the lack of an untreated control group, the absolute CVD risk related to either febuxostat or allopurinol is unknown. There was a bias of incompleteness because of high dropout rates in both the febuxostat and allopurinol groups. Febuxostat had been reinforced to the maximum dose of $60 \mathrm{mg} /$ day; however, 
allopurinol had been increased to a dose less than its maximum value, because $52.8 \%$ of enrolled patients had CKD, indicating the impaired validity of this study protocol. A large observational study in the USA did not show an increased risk of CVD or all-causes mortality associated with febuxostat compared with allopurinol. ${ }^{72}$ Another study using a managed care database demonstrated a lower risk of a CVD event among febuxostat initiators than allopurinol initiators. ${ }^{73}$ Taken together with the FEATHER ${ }^{8}$ study and FREED study ${ }^{70}$ in Japanese patients, there was not any difference in mortality between the febuxostat group and the placebo or allopurinol groups, thus, it may not be recommended to switch using febuxostat to an alternative oral ULA in patients with a history of CVD. The ongoing FAST trial ${ }^{74}$ in Europe serves to confirm the cardiovascular safety of allopurinol and febuxostat in the management of gout.

Although the key issue in the CARES study ${ }^{71}$ was the higher CVD death rates and all-causes mortality in Americans treated with febuxostat vs. allopurinol, the data that attracted attention was a drastic increase in major adverse CVD events after quitting these drugs when subjects went "off-drug". ${ }^{75,76}$ It has been reported that the mean percentage of CV death in patients was $0.17 \%$ and $0.085 \%$ per month for 4 years with febuxostat and allopurinol, respectively. ${ }^{76}$ This rate increased to $2.19 \%$ and $1.56 \%$ per month, respectively, during the first 30 off-drug days. A similar trend was observed in subsequent time periods up to 180 days off-drug. The possibility of "XO inhibitor withdrawal syndrome" was proposed, as has $\beta$-blocker withdrawal. ${ }^{77}$ Although further studies are necessary to confirm "XO inhibitor withdrawal syndrome", it is not recommended to quit either allopurinol or febuxostat once administration to patients has commenced.

\section{Conclusions}

Despite the role of UA as an antioxidant, hyperuricemia impairs endothelial function via an accumulation of intracellular UA and XO, which may cause vascular diseases. Recommendations on ULAs differ between the JGMHG 3rd edition and ACR2020. Although both guidelines have been developed based on the GRADE method, the difference is attributable to the different situation of the Medicare systems and patient opinion between the 2 countries. The JGMHG 3rd edition recommends pharmacological treatment of hyperuricemia in patients with CKD, emphasizing the importance of the cardio-renal continuum for treatment of asymptomatic hyperuricemia patients with hypertension and heart failure. In order to reduce mortality in hyperuricemic patients with either hypertension or heart failure, ULAs could be used, when patients agree. Further RCTs are needed to study the rationality of using ULAs to improve the prognosis of hyperuricemic patients with CVD.

\section{Disclosures}

Dr. Hisatome is a member of Circulation Journal's Editorial Team. Dr. Hisatome reports having received lecturing fees from Sanwa Kagaku Kenkyusho Co. Ltd., Mochida Co. Ltd., and Fuji Yakuhin Co. Ltd., and research grants from Teijin Pharma Ltd., Fuji Yakuhin Co. Ltd. and Sanwa Kagaku Kenkyusho Co. Ltd.

\section{References}

1. Yamanaka H. Japanese guideline for the management of hyperuricemia and gout: Second edition. Nucleosides Nucleotides Nucleic Acids 2011; 30: 1018-1029.

2. FitzGerald JD, Dalbeth N, Mikuls T, Brignardello-Petersen R, Guyatt G, Abeles AM, et al. 2020 American College of Rheumatology Guideline for the Management of Gout. Arthritis Care Res (Hoboken) 2020; 72: 744-760.

3. Hisatome I, Ichida K, Mineo I, Ohtahara A, Ogino K, Kuwabara M, et al. Japanese Society of Gout and Uric \& Nucleic Acids 2019 Guidelines for Management of Hyperuricemia and Gout 3rd edition. Gout and Uric \& Nucleic Acids 2020; 44: sp-1 -sp-40.

4. Allen DJ, Milosovich G, Mattocks AM. Inhibition of monosodium urate needle crystal growth. Arthritis Rheum 1965; 8: 1123-1133.

5. Loeb JN. The influence of temperature on the solubility of monosodium urate. Arthritis Rheum 1972; 15: 189-192.

6. Seegmiller JE. The acute attack of gouty arthritis. Arthritis Rheum 1965; 8: 714-725.

7. Campion EW, Glynn RJ, DeLabry LO. Asymptomatic hyperuricemia: Risks and consequences in the Normative Aging Study. Am J Med 1987; 82: 421-426.

8. Kimura $\mathrm{K}$, Hosoya $\mathrm{T}$, Uchida $\mathrm{S}$, Inaba M, Makino $\mathrm{H}$, Maruyama S, et al. Febuxostat therapy for patients with stage 3 $\mathrm{CKD}$ and asymptomatic hyperuricemia: A randomized trial. Am J Kidney Dis 2018; 72: 798-810.

9. Perez-Ruiz F, Calabozo M, Erauskin GG, Ruibal A, HerreroBeites AM. Renal underexcretion of uric acid is present in patients with apparent high urinary uric acid output. Arthritis Rheum 2002; 47: 610-613.

10. Ichida K, Matsuo H, Takada T, Nakayama A, Murakami K, Shimizu T, et al. Decreased extra-renal urate excretion is a common cause of hyperuricemia. Nat Commun 2012; 3: 764.

11. Matsuo H, Takada T, Ichida K, Nakamura T, Nakayama A, Ikebuchi Y, et al. Common defects of ABCG2, a high-capacity urate exporter, cause gout: A function-based genetic analysis in a Japanese population. Sci Transl Med 2009; 1: 5ra11.

12. Grayson PC, Kim SY, LaValley M, Choi HK. Hyperuricemia and incident hypertension: A systematic review and meta-analysis. Arthritis Care Res (Hoboken) 2011; 63: 102-110.

13. Lv Q, Meng XF, He FF, Chen S, Su H, Xiong J, et al. High serum uric acid and increased risk of type 2 diabetes: A systemic review and meta-analysis of prospective cohort studies. PLoS One 2013; 8: e56864.

14. Yuan H, Yu C, Li X, Sun L, Zhu X, Zhao C, et al. Serum uric acid levels and risk of metabolic syndrome: A dose-response meta-analysis of prospective studies. J Clin Endocrinol Metab 2015; 100: 4198-4207.

15. Jensen T, Niwa K, Hisatome I, Kanbay M, Andres-Hernando A, Roncal-Jimenez CA, et al. Increased serum uric acid over five years is a risk factor for developing fatty liver. Sci Rep 2018; 8: 11735.

16. Zhu P, Liu Y, Han L, Xu G, Ran JM. Serum uric acid is associated with incident chronic kidney disease in middle-aged populations: A meta-analysis of 15 cohort studies. PLoS One 2014; 9: e100801.

17. Li M, Hu X, Fan Y, Li K, Zhang X, Hou W, et al. Hyperuricemia and the risk for coronary heart disease morbidity and mortality a systematic review and dose-response meta-analysis. Sci Rep 2016; 6: 19520 .

18. Huang H, Huang B, Li Y, Huang Y, Li J, Yao H, et al. Uric acid and risk of heart failure: A systematic review and meta-analysis. Eur J Heart Fail 2014; 16: 15-24.

19. Kuwabara M, Niwa K, Nishihara S, Nishi Y, Takahashi O, Kario K, et al. Hyperuricemia is an independent competing risk factor for atrial fibrillation. Int J Cardiol 2017; 231: 137-142.

20. Choi HK, Ford ES. Haemoglobin Alc, fasting glucose, serum C-peptide and insulin resistance in relation to serum uric acid levels: The Third National Health and Nutrition Examination Survey. Rheumatology (Oxford) 2008; 47: 713-717.

21. Enomoto A, Kimura H, Chairoungdua A, Shigeta Y, Jutabha P, $\mathrm{Cha} \mathrm{SH}$, et al. Molecular identification of a renal urate anion exchanger that regulates blood urate levels. Nature 2002; 417: 447-452.

22. Muscelli E, Natali A, Bianchi S, Bigazzi R, Galvan AQ, Sironi AM, et al. Effect of insulin on renal sodium and uric acid handling in essential hypertension. Am J Hypertens 1996; 9: 746-752.

23. Toyoki D, Shibata S, Kuribayashi-Okuma E, Xu N, Ishizawa K, Hosoyamada M, et al. Insulin stimulates uric acid reabsorption via regulating urate transporter 1 and ATP-binding cassette subfamily G member 2. Am J Physiol Renal Physiol 2017; 313: F826-F834.

24. Maruhashi T, Hisatome I, Kihara Y, Higashi Y. Hyperuricemia and endothelial function: From molecular background to clinical 
perspectives. Atherosclerosis 2018; 278: 226-231.

25. Vane JR, Anggård EE, Botting RM. Regulatory functions of the vascular endothelium. $N$ Engl J Med 1990; 323: 27-36.

26. Ross R. Atherosclerosis: An inflammatory disease. $N$ Engl J Med 1999; 340: 115-126.

27. Maruhashi T, Nakashima A, Soga J, Fujimura N, Idei N, Mikami S, et al. Hyperuricemia is independently associated with endothelial dysfunction in postmenopausal women but not in premenopausal women. BMJ Open 2013; 3: e003659.

28. Kato M, Hisatome I, Tomikura Y, Kotani K, Kinugawa T, Ogino K, et al. Status of endothelial dependent vasodilation in patients with hyperuricemia. Am J Cardiol 2005; 96: 1576-1578

29. Warning WS, Webb DJ, Maxwell SRJ. Effect of local hyperuricemia on endothelial function in the human vascular bed. $\mathrm{Br} J$ Clin Pharmacol 2000; 59: 511.

30. Nakagawa T, Hu H, Zharikov S, Tuttle KR, Short RA, Glushakova $\mathrm{O}$, et al. A causal role for uric acid in fructose-induced metabolic syndrome. Am J Physiol Renal Physiol 2006; 290: F625-F631.

31. Papežíková I, Pekarová M, Kolářová $H$, Klinke A, Lau D, Baldus S, et al. Uric acid modulates vascular endothelial function through the down regulation of nitric oxide production. Free Radic Res 2013; 47: 82-88.

32. Mishima M, Hamada T, Maharani N, Ikeda N, Onohara T, Notsu T, et al. Effects of uric acid on the NO production of HUVECs and its restoration by urate lowering agents. Drug Res (Stuttg) 2016; 66: 270-274.

33. Anzai N, Ichida K, Jutabha P, Kimura T, Babu E, Jin CJ, et al. Plasma urate level is directly regulated by a voltage-driven urate efflux transporter URATv1 (SLC2A9) in humans. J Biol Chem 2008; 283: 26834-26838.

34. Nakamura M, Anzai N, Jutabha P, Sato H, Sakurai H, Ichida $\mathrm{K}$. Concentration-dependent inhibitory effect of irbesartan on renal uric acid transporters. J Pharmacol Sci 2010; 114: 115-118.

35. Maharani N, Kuwabara M, Hisatome I. Hyperuricemia and atrial fibrillation. Int Heart J 2016; 57: 395-399.

36. Kang DH, Han L, Ouyang X, Kahn AM, Kanellis J, Li P, et al. Uric acid causes vascular smooth muscle cell proliferation by entering cells via a functional urate transporter. Am J Nephrol 2005; 25: 425-433.

37. Taufiq F, Maharani N, Li P, Kurata Y, Ikeda N, Kuwabara M, et al. Uric acid-induced enhancements of Kv1.5 protein expression and channel activity via the Akt-HSF1-Hsp70 Pathway in HL-1 atrial myocytes. Circ J 2019; 83: 718-726.

38. Kang DH, Park SK, Lee IK, Johnson RJ. Uric acid-induced C-reactive protein expression: Implication on cell proliferation and nitric oxide production of human vascular cells. $J$ Am Soc Nephrol 2005; 16: 3553-3562.

39. Sessa WC. eNOS at a glance. J Cell Sci 2004; 117: 2427-2429.

40. Li P, Zhang L, Zhang M, Zhou C, Lin N. Uric acid enhances PKC-dependent eNOS phosphorylation and mediates cellular ER stress: A mechanism for uric acid-induced endothelial dysfunction. Int J Mol Med 2016; 37: 989-997.

41. Zhou Y, You H, Zhang A, Jiang X, Pu Z, Xu G, et al. Lipoxin A4 attenuates uric acid-activated, NADPH oxidase-dependent oxidative stress by interfering with translocation of p47phox in human umbilical vein endothelial cells. Exp Ther Med 2020; 20: $1682-1692$

42. Berry CE, Hare JM. Xanthine oxidoreductase and cardiovascular disease: Molecular mechanisms and pathophysiological implications. J Physiol 2004; 555: 589-606.

43. Forstermann U, Sessa WC. Nitric oxide synthases: Regulation and function. Eur Heart $J$ 2012; 33: 829-837, 837a-837d.

44. Furuhashi M, Matsumoto M, Tanaka M, Moniwa N, Murase T, Nakamura T, et al. Plasma xanthine oxidoreductase activity as a novel biomarker of metabolic disorders in a general population. Circ J 2018; 82: 1892-1899.

45. Houston M, Estevez A, Chumley P, Aslan M, Marklund S, Parks DA, et al. Binding of xanthine oxidase to vascular endothelium. Kinetic characterization and oxidative impairment of nitric oxide-dependent signaling. J Biol Chem 1999; 274: 4985-4994

46. White CR, Brock TA, Chang LY, Crapo J, Briscoe P, Ku D, et al. Superoxide and peroxynitrite in atherosclerosis. Proc Natl Acad Sci USA 1994; 91: 1044-1048.

47. Glantzounis GK, Tsimoyiannis EC, Kappas AM, Galaris DA. Uric acid and oxidative stress. Curr Pharm Des 2005; 11: 4145 4151.

48. Hink HU, Santanam N, Dikalov S, McCann L, Nguyen AD, Parthasarathy S, et al. Peroxidase properties of extracellular superoxide dismutase: Role of uric acid in modulating in vivo activity. Arterioscler Thromb Vasc Biol 2002; 22: 1402-1408.

49. Sugihara S, Hisatome I, Kuwabara M, Niwa K, Maharani N, Kato M, et al. Depletion of uric acid due to SLC22A12 (URAT1) loss-of-function mutation causes endothelial dysfunction in hypouricemia. Circ J 2015; 79: 1125-1132.

50. Ishikawa I. Acute renal failure with severe loin pain and patchy renal ischemia after anaerobic exercise in patients with or without renal hypouricemia. Nephron 2002; 91: 559-570.

51. Verdecchia P, Schillaci G, Reboldi G, Santeusanio F, Porcellati C, Brunetti P. Relation between serum uric acid and risk of cardiovascular disease in essential hypertension: The PIUMA study. Hypertension 2000; 36: 1072-1078.

52. Kuwabara M, Hisatome I, Niwa K, Bjornstad P, RoncalJimenez CA, Andres-Hernando A, et al. The optimal range of serum uric acid for cardiometabolic diseases: A 5-year Japanese cohort study. J Clin Med 2020; 9: 942

53. Sivera F, Andrés M, Carmona L, Kydd AS, Moi J, Seth R, et al. Multinational evidence-based recommendations for the diagnosis and management of gout: Integrating systematic literature review and expert opinion of a broad panel of rheumatologists in the $3 \mathrm{e}$ initiative. Ann Rheum Dis 2014; 73: 328-335.

54. Levy G, Shi JM, Cheetham TC, Rashid N. Urate-lowering therapy in moderate to severe chronic kidney disease. Perm J 2018; 22: 17-142.

55. Abeles AM, Pillinger MH. Gout and cardiovascular disease: Crystallized confusion. Curr Opin Rheumatol 2019; 31: 118124.

56. Schünemann H, Brożek J, Guyatt G, Oxman A. GRADE handbook for Grading quality of evidence and strength of recommendations. The GRADE Working Group 2013. https:// gdt.gradepro.org/app/handbook/handbook.html (accessed May 2, 2020).

57. Fukui T, Yamaguchi N. Minds handbook for clinical practice guideline development. Tokyo: Japanese Minds Guideline Center, Japan Council for Quality Health Care, 2014.

58. Goicoechea M, de Vinuesa SG, Verdalles U, Ruiz-Caro C, Ampuero J, Rincon A, et al. Effect of allopurinol in chronic kidney disease progression and cardiovascular risk. Clin J Am Soc Nephrol 2010; 5: 1388-1393.

59. Shi Y, Chen W, Jalal D, Li Z, Chen W, Mao H, et al. Clinical outcome of hyperuricemia in IgA nephropathy: A retrospective cohort study and randomized controlled trial. Kidney Blood Press Res 2012; 35: 153-160.

60. Hosoya T, Ohno I, Nomura S, Hisatome I, Uchida S, Fujimori $\mathrm{S}$, et al. Effects of topiroxostat on the serum urate levels and urinary albumin excretion in hyperuricemic stage 3 chronic kidney disease patients with or without gout. Clin Exp Nephrol 2014; 18: 876-884.

61. Liu P, Chen Y, Wang B, Zhang F, Wang D, Wang Y. Allopurinol treatment improves renal function in patients with type 2 diabetes and asymptomatic hyperuricemia: 3-year randomized parallelcontrolled study. Clin Endocrinol (Oxf) 2015; 83: 475-482.

62. Sircar D, Chatterjee S, Waikhom R, Golay V, Raychaudhury A Chatterjee S, et al. Efficacy of Febuxostat for slowing the GFR decline in patients with CKD and asymptomatic hyperuricemia: A 6-month, double-blind, randomized, placebo-controlled trial. Am J Kidney Dis 2015; 66: 945-950.

63. Siu YP, Leung KT, Tong MK, Kwan TH. Use of allopurinol in slowing the progression of renal disease through its ability to lower serum uric acid level. Am J Kidney Dis 2006; 47: 51 - 59.

64. Saag KG, Whelton A, Becker MA, MacDonald P, Hunt B, Gunawardhana L. Impact of Febuxostat on renal function in gout patients with moderate-to-severe renal impairment. Arthritis Rheumatol 2016; 68: 2035-2043.

65. Terawaki H, Nakayama M, Miyazawa E, Murata Y, Nakayama $\mathrm{K}$, Matsushima M, et al. Effect of allopurinol on cardiovascular incidence among hypertensive nephropathy patients: The Gonryo study. Clin Exp Nephrol 2013; 17: 549-553.

66. MacIsaac RL, Salatzki J, Higgins P, Walters MR, Padmanabhan S, Dominiczak AF, et al. Allopurinol and cardiovascular outcomes in adults with hypertension. Hypertension 2016; 67: 535-540.

67. Gois PHF, Souza ERM. Pharmacotherapy for hyperuricemia in hypertensive patients. Cochrane Database Syst Rev 2017; 4: CD008652.

68. Hare JM, Mangal B, Brown J, Fisher C Jr, Freudenberger R, Colucci WS, et al. Impact of oxypurinol in patients with symptomatic heart failure: Results of the OPT-CHF study. $J$ Am Coll Cardiol 2008; 51: 2301-2309.

69. Givertz MM, Anstrom KJ, Redfield MM, Deswal A, Haddad H, Butler J, et al. Effects of xanthine oxidase inhibition in hyperuri- 
cemic heart failure patients: The Xanthine Oxidase Inhibition for Hyperuricemic Heart Failure Patients (EXACT-HF) Study. Circulation 2015; 131: 1763-1771.

70. Kojima S, Matsui K, Hiramitsu S, Hisatome I, Waki M, Uchiyama $\mathrm{K}$, et al. Febuxostat for Cerebral and CaRdiorenovascular Events PrEvEntion StuDy. Eur Heart J 2019; 40: 1778-1786.

71. White WB, Saag KG, Becker MA, Borer JS, Gorelick PB, Whelton A, et al. Cardiovascular safety of febuxostat or allopurinol in patients with gout. $N$ Engl J Med 2018; 378: 1200-1210.

72. Zhang M, Solomon DH, Desai RJ, Kang EH, Liu J, Neogi T, et al. Assessment of cardiovascular risk in older patients with gout initiating febuxostat versus allopurinol: Population-based cohort study. Circulation 2018; 138: 1116-1126.

73. Foody J, Turpin RS, Tidwell BA, Lawrence D, Schulman KL Major cardiovascular events in patients with gout and associated cardiovascular disease or heart failure and chronic kidney disease initiating a xanthine oxidase inhibitor. Am Health Drug Benefits 2017; 10: 393-401.
74. MacDonald TM, Ford I, Nuki G, Mackenzie IS, De Caterina R, Findlay E, et al. Protocol of the Febuxostat versus Allopurinol Streamlined Trial (FAST): A large prospective, randomised, open, blinded endpoint study comparing the cardiovascular safety of allopurinol and febuxostat in the management of symptomatic hyperuricaemia. BMJ Open 2014; 4: e005354.

75. Bubb MR. Excess deaths upon cessation of xanthine oxidase inhibitor treatment-Data from the cardiovascular safety of febuxostat and allopurinol in patients with gout and cardiovascular morbidities trial: Comment on the Article by Choi et al. Arthritis Rheumatol 2019; 71: 1391-1392.

76. Johnson TA, Kamatani N, Kuwabara M. Xanthine oxidase inhibitor withdrawal syndrome? Comment on the Article by Choi et al. Arthritis Rheumatol 2019; 71: 1966-1967.

77. Prins KW, Neill JM, Tyler JO, Eckman PM, Duval S. Effects of beta-blocker withdrawal in acute decompensated heart failure: A systematic review and meta-analysis. JACC Heart Fail 2015; 3: $647-653$. 